Ensino e Geografia

\title{
Educação Geográfica: Concepções de professores de Geografia na Rede Estadual em Francisco Beltrão-PR
}

\author{
Geographic Education: Conception of Geography teachers in the State \\ Network in Francisco Beltrão-PR
}

\section{Jalme Santana de Figueiredo Junior ${ }^{10}$, Najla Mehanna Mormul"(i), Rosana Cristina Biral Leme"}

'Escola Estadual Professor Fernando Leite de Campos, Várzea Grande, MT, Brasil

"Universidade Estadual do Oeste do Paraná - UNIOESTE, curso de Geografia Licenciatura Campus de Francisco Beltrão, PR, Brasil

\section{RESUMO}

No decorrer de 2018 a 2019 foi realizado um estudo de caso, junto aos professores de Geografia, pertencentes ao Quadro Próprio do Magistério (QPM) do Estado do Paraná, atuantes no Município de Francisco Beltrão. O principal objetivo buscou identificar quais concepções de Educação Geográfica orientavam as práticas docentes desses profissionais. Partindo de uma perspectiva de pesquisa qualitativa, desenvolveram-se questionários e entrevistas junto 29 (vinte e nove) de um total de 35 (trinta e cinco) professores efetivos. Pode-se identificar três categorias centrais: materialismo histórico e dialético, histórico ambiental e subjetivo/fenomenológico. Nesse texto, será apresentado os procedimentos e referências utilizados na pesquisa, que possibilitaram identificar uma prática docente pautada no compromisso teórico, prático e de transformação social por parte dos profissionais entrevistados.

Palavras-chave: Educação Geográfica. Professores de Geografia. Educação Básica

\section{ABSTRACT}

In the course of 2018 to 2019, a case stuy was carried out with the Geography teachers, belonging to the Teaching Staff the State of Paraná, working in Municipality of Francisco Beltrão. The main objective was to identify which conceptions of Geographic Education guided the teaching practices of these professionals. Starting from a qualitative research perspective, questionnaires and interviews were devolopd with 29 out of 35 effective teachers. Three central categories can be identified: historical na dialectical materialism, environmental history and subjective/phenomenological. In this text, the procedures and references used in the research will be presented, which made it possible to identify a 
teaching practice based on the theoretical, practical and social transformation commitment by the professionals interviewed.

Keywords: Geographic Education; Geography Teachers; Basic education

\section{INTRODUÇÃO}

Esse texto é fruto da dissertação de mestrado defendida em 29 de julho de 2019, junto ao Programa de Pós-Graduação Stricto Senso em Geografia da Universidade Estadual do Oeste do Paraná (UNIOESTE), Campus de Francisco Beltrão objetivou-se apresentar as concepções de Educação geográfica que norteiam as práticas docentes dos professores(as) de Geografia, atuantes na Educação Básica em Francisco Beltrão/PR.

Foi realizado estudo de caso, pois se mostrou uma proposta metodológica adequada para alcançar o objetivo almejado. Yin (2001, p.21) expõe "[...] o estudo de caso permite uma investigação para se preservar as características holísticas e significativas dos eventos da vida real". Além de possibilitar a visualização holística do fenômeno, também articula aspectos qualitativos e quantitativos uma vez que, segundo Godoy (1995, p.26), "ainda que os estudos de caso sejam, em essência, pesquisa de caráter qualitativo, podem comportar dados quantitativos para aclarar algum aspecto da questão investigada".

A metodologia de estudo proposta foi articulada ao método dialético, por entender que: "A história se move por leis necessárias e objetivas, mas a par de seu lado objetivo natural, possui o lado subjetivo, político, de conquista humana e cultural" (DEMO, 2012, p.89).

A produção de uma pesquisa não se ancora em uma perspectiva neutra, pois o pesquisador e o objeto investigado estão em interação (DEMO, 2012). Tratandose de pesquisas no ensino, essa linha se mostra ainda mais tênue.

Portanto, esse estudo voltou-se para um fenômeno contemporâneo e específico da vida, ou seja, as concepções de Educação Geográfica que norteiam a 
prática docente, analisados dentro de uma conjuntura política e social, própria aos professores de Geografia da rede estadual de educação de Francisco Beltrão-PR.

Valendo-se de questionários e entrevistas, foram inquiridos vinte e nove profissionais efetivos que exerciam docência em Geografia na Educação Básica Estadual em Francisco Beltrão. O número total de professores era trinta e dois, no entanto, alguns estavam de licença médica e/ou férias, portanto, não participaram da pesquisa.

Foi assinado um Termo de Consentimento Livre e Esclarecido (TCLE), garantindo o anonimato dos participantes e a utilização das informações coletadas apenas para finalidades acadêmicas científicas. Suas contribuições para o estudo foram citados de modo não nominalmente, utilizando o rol das vinte e seis letras do alfabeto da língua portuguesa.

Foram realizadas vinte e nove entrevistas, considerando que o alfabeto oficial possui vinte e seis letras após a utilização de todas as letras (cada uma correspondendo um entrevistado) o alfabeto foi retomado incluindo sequência numérica.

O questionário desenvolvido era estruturado, as primeiras questões eram fechadas: Nome; instituição e ano de conclusão da graduação; se tinha pósgraduação - onde cursou, em que área foi e ano que finalizou; quanto tempo trabalha na rede pública e em quantas escolas atuava naquele momento. As questões finais eram discursivas, uma falava sobre as principais dificuldades para se trabalhar o ensino de Geografia, a outra, o que seria Educação Geográfica na leitura do questionado.

Além do questionário, foi realizada uma entrevista aberta partindo de uma dinâmica de conversa visto que “(...) o informante é convidado a falar livremente sobre um tema, e as perguntas quando feitas buscam dar mais profundidade à reflexões". (MINAYO, 2016, p.59).

As questões norteadoras da entrevista foram: 1) Qual o papel da Geografia na atualidade? 2) Qual o papel do ensino da geografia na atualidade? 3) Em sua 
leitura, quais são as principais dificuldades para trabalhar os conhecimentos geográficos em sala de aula?

Esse roteiro de questões não foi disponibilizado previamente aos professores(as). A conversa foi gravada para facilitar a transcrição posteriormente. Os(as) participantes foram elucidados(as) quanto aos objetivos e procedimentos da pesquisa, assinando termos de consentimento e livre esclarecimento, resguardando assim o direito ao anonimato para finalidades acadêmicas e científicas

A análise dos dados obtidos, com o questionário e entrevista, foram empreendidos a partir da leitura de documentos oficiais (que contextualizavam legalmente o trabalho docente dos participantes) e pela sistematização dos dados a partir de seus conteúdos - sobretudo os dados flutuantes e posteriormente a categorização (BARDIN, 2011).

Os três aspectos principais para a análise documental foi "a escolha dos documentos, o acesso a eles e a sua análise" (GODOY, 1995, p.23). Foram escolhidos: a Constituição Federal de 1988, Constituição do Paraná de 1989, a Lei de Diretrizes e bases da Educação n 9.394 de 1996, a Lei complementar 103 de 15 de março de 2004 que dispões sobre o plano de carreira e ingresso no magistério estadual na Educação Básica do Paraná, Diretrizes Estaduais para o Ensino de Geografia (2008), dentre outros que serão apresentados oportunamente no decorrer do texto.

Essa análise respaldou a descoberta das concepções, possibilitando uma categorização das mesmas. Essa categorização considerou referencial teórico estudado articulados a visão apresentada no conteúdo coletado. As ações desenvolvidas, diálogo com orientadores, estudo e trocas de experiências, possibilitou sugerir três categorias de concepções principais: materialismo histórico e dialético; subjetivo e fenomenológico; histórico ambiental. 


\section{PONTO DE PARTIDA: CONTEXTO DAS CONCEPÇÕES ENCONTRADAS}

É interessante compreender as concepções norteadoras de práticas docentes a partir das relações complexas que a cercam, visto que, "O mundo tornase, cada vez mais, um todo. Cada parte do mundo faz, mais e mais, parte do mundo, e o mundo, como um todo, está, cada vez mais presente em cada uma de suas partes" (MORIN, 2011, p.58).

Identificar as concepções de Educação Geográfica por parte dos profissionais que ensinam geografia na Educação Básica, suscita observar marcos institucionais e curriculares no Brasil, a partir da década de 1990. A escolha desse recorte temporal se deu pois, tal período possui fortes influências nos modelos e prestação de serviços educacionais na atualidade.

Foi no decorrer da década de 1980 e 1990 que se observa a realização do Consenso de Washington de 1989 e seus desdobramentos na educação, sobretudo pela Declaração Mundial sobre Educação para Todos (Conferência de Jontien 1990) e o Relatório para Unesco da Comissão Internacional sobre Educação para o século XXI (educação um tesouro a Descobrir). Esses eventos, podem ser considerado pedras de toque no que tratam influências políticas e econômicas na prestação de serviços educacionais e nos modelos vigentes nos países periféricos.

Ocorrido em novembro de 1989, nos Estados Unidos, o Consenso de Washington foi conduzido por funcionários do governo estadunidense e membros dos principais organismos financeiros da época - Fundo Monetário Internacional (FMI), Banco Mundial (BM) e Banco Interamericano de Desenvolvimento (BID). Este grupo criou um conjunto de orientações e reformas que os países periféricos do Capitalismo deferiam realizar para resolver seus problemas sociais e econômicos estruturais: 
O Objetivo do encontro, convocado pelo Institute for International Economics, sob título "Latin American Adjustmente: How Much has Happended?", era proceder a uma avaliação das reformas econômicas empreendidas nos países da região. Para relatar a experiência de seus países, também estiveram presentes diversos economistas latino-americanos. Às conclusões dessa reunião é que se daria, subsequentemente, a denominação informal de "Consenso de Washington". (BATISTA, 1995, p. 99-100).

Do receituário produzido, destacam-se os pontos principais: "1. Disciplina fiscal; 2. Priorização financeira; 5. Regime cambial; 6. Liberalização comercial; 7. Investimento direto estrangeiro; 8. Privatização; 9. Desregulação; e 10. Propriedade intelectual" (BATISTA, 1995, p.118).

Esse conjunto de políticas, que se popularizou pelo nome Neoliberalismo, influenciou sobremaneira os governos em países da América do Sul, principalmente o Brasil. Essas políticas de redução do Estado partiam da interpretação que "Tudo em nome de um grande princípio: o da soberania absoluta do mercado auto regulável nas relações econômicas tanto internas quanto externas" (BATISTA, 1995, p.119).

$\mathrm{Na}$ educação o desdobramento do Consenso foi a Declaração de Jontien de 1990. Coadunando com narrativas produzidas pelos neoliberais, a Declaração de 1990 apresentou quatro problemáticas para que interferiam na prestação qualitativa de serviços educacionais em países periféricos:

- Mais de 100 milhões de crianças, das quais pelo menos 60 milhões são meninas, não têm acesso ao ensino primário;

- Mais de 960 milhões de adultos - dois terços dos quais mulheres são analfabetos, e o analfabetismo funcional é um problema significativo em todos os países industrializados ou em desenvolvimento;

- Mais de um terço dos adultos do mundo não tem acesso aos conhecimento impresso, às novas habilidades e tecnologias, que poderiam melhorar a qualidade de vida e ajuda-los a perceber e a adaptar-se às mudanças sociais e culturais; e

- Mais de 100 milhões de crianças e contáveis adultos não conseguem concluir o ciclo básico, e outros milhões, apesar de concluí-lo, não conseguem adquirir conhecimento e habilidades essenciais. (WCEFA, 1990, S/P).

Os envolvidos com a produção da Declaração, indicavam problemas de ordem social - apontando como solução aspectos estritamente econômicos. Em grande medida, fomentaram interpretações técnicas e economicistas das 
principais questões sociais geradas pelos altos níveis de desigualdade mundial (NETO, 2003).

Outro documento elucidativo e de grande força política foi o Relatório Educação um tesouro a Descobrir (ETD), também produzido sob auspícios dos representantes do Consenso de Washington, esse documento foi elaborado na Conferência de Jontien - Tailândia em 1998.

As interpretações apresentadas na Conferência - em forma do Relatório ETD, se sustentavam em perspectivas resolutivas dos grandes problemas gerados pela desigualdade mundial, mais uma vez, eram vetores econômicos os responsáveis por tal superação. O documento trazia, de modo evidente, a formação de uma sociedade mundial em torno de uma mesma base, coesão social, participação democrática, crescimento econômico e desenvolvimento humano (DELORS et al., 1998).

É possível observar a necessidade em formar cidadãos para o mundo, considerando uma comunicação universal e, ao mesmo tempo, articulada entre global e local. Evidencia-se a valorização de aspectos como empatia e a formação de um capital humano para a produtividade, conforme:

Observa-se, de fato, que no decurso do período considerado e sob a pressão do progresso técnico e da modernização, a procura de educação com fins econômicos não parou de crescer na maior parte dos países. As comparações internacionais realçam a importância do capital humano, e portanto, do investimento educativo para a produtividade. A relação entre o ritmo do progresso técnico e a qualidade da intervenção humana, torna-se, então, cada vez mais evidente, assim como a necessidade de formar agentes econômicos aptos a utilizar novas tecnologias e que revelem um comportamento inovador. (DELORS et al., 1998, p. 70-71).

O relatório orienta a educação do século XXI enquanto uma atividade educativa e formativa, voltada para o desenvolvimento econômico dos países periféricos. Busca potencializar e ampliar os índices econômicos internacionais: “No alvorecer do século XXI, a atividade educativa e formativa, em todos os seus componentes, tornou-se um dos motores principais do desenvolvimento" (DELORS et al., 1998, p.72). 
Percebe-se caráter ideológico nos documentos expostos, visto que não esclarece, objetivamente, os meios de implementação e financiamento da execução das propostas. Não indica a formação crítica e democrática do cidadão, mas sua operacionalidade enquanto mão-de-obra produtiva a baixos custos. A ação política das pessoas não é compreendida enquanto correlações de enfrentamento hegemônico, mas sim como uma peça para o mercado (SANTOS, 2017).

Grande parte dos encontros e conferências realizados em âmbitos mundiais na década de 1990, davam centralidade a Educação, principalmente a Educação Básica. Eram propostas reformas que inseriam processos educativos na lógica de mercado. As principais organizações financeiras internacionais, condicionavam empréstimos e financiamentos aos países mediante essas adequações, conforme ocorreu no Brasil - no contexto de produção da nova Lei de Diretrizes e Bases da Educação Nacional (LDBN n 9394/1996), os Parâmetros Curriculares Nacionais de 1997 e Diretrizes Curriculares Nacionais para o Ensino Médio de 1998 (DCE, 2008).

Os principais marcos representativos, de orientação ao ensino de Geografia na Educação Básica no país (a partir da redemocratização) estavam vinculados a essas perspectivas internacionais (JESUS, 2014). Tanto a Conferência de Jontien, Relatório Educação um Tesouro a Descobrir e o Consenso de Washington de 1989, impactaram muito na produção de indicativos internacionais para a Educação Geográfica. (GONZÁLES e CLAUDINO, 2002).

Evidencia-se a Carta Internacional pela Educação Geográfica (1992), a Nova Carta Internacional sobre Educação Geográfica (2000), a $4^{\text {a }}$ Conferência Internacional da Unesco em Genebra - "Aprender a viver juntos: será que fracassamos?" (2011) e a Declaração de Lucerne (2007), enquanto movimentos importantes na compreensão da Educação Geográfica divulgada institucionalmente nos países (GONZÁLES e CLAUDINO, 2002).

Essas ações políticas internacionais, podem contextualizar aspectos vinculados aos Parâmetros Curriculares Nacionais (1997) e as Diretrizes 
Curriculares da Educação Básica de Geografia do Estado do Paraná (2008). As orientações contidas nessas proposições, colabora na compreensão das concepções de Educação Geográfica presente nas falas dos(as) professores(as) participantes do estudo de caso desenvolvido.

Em torno desses documentos internacionais, são dois pontos de convergência identificados: uma crítica direta ao ensino de Geografia pautado na memorização, descrição e apartado do contexto de vida dos estudantes e outro vinculado as interpretações desdobradas da Conferência de Jontien, Consenso de Washington e do Relatório Educação um Tesouro a Descobrir (FIGUEIREDO JUNIOR, 2019).

As análises empreendidas embasaram a elaboração do Quadro 01, organizado a partir do título de cada um dos documentos, divididos por categorias centrais em torno da Concepção Orientadora, Objetivos, Papel da Geografia, Organização curricular e Responsabilidade pelo Ensino.

Quadro 01 - Documentos internacionais sobre Educação Geográfica e suas orientações para os países periféricos

\begin{tabular}{|c|c|c|c|c|}
\hline DOCUMENTO & $\begin{array}{l}\text { CARTA SOBRE A } \\
\text { EDUCAÇÃO } \\
\text { GEOGRÁFICA (1992) }\end{array}$ & $\begin{array}{c}\text { II CARTA } \\
\text { INTERNACIONAL PELA } \\
\text { EDUCAÇÃO } \\
\text { GEOGRÁFICA (2000) }\end{array}$ & $\begin{array}{c}\text { 46 } 6^{\mathrm{a}} \text { CONFERÊNCIA } \\
\text { INTERNACIONAL DA } \\
\text { UNESCO EM GENEBRA } \\
(2001)\end{array}$ & $\begin{array}{l}\text { DECLARAÇÃO DE } \\
\text { LUCERNE } 2007\end{array}$ \\
\hline $\begin{array}{l}\text { Concepção } \\
\text { Orientadora }\end{array}$ & $\begin{array}{c}\text { Princípios de } \\
\text { dignidade, } \\
\text { igualdade e } \\
\text { equidade a nível } \\
\text { mundial e homem } \\
\text { parte da natureza. }\end{array}$ & $\begin{array}{l}\text { Interface entre } \\
\text { homem e } \\
\text { natureza em uma } \\
\text { ótica amigável. }\end{array}$ & $\begin{array}{l}\text { Baseado na ideia } \\
\text { de educação para } \\
\text { a diversidade } \\
\text { cultural. }\end{array}$ & $\begin{array}{l}\text { Baseada no } \\
\text { conceito do } \\
\text { ecossistema } \\
\text { "Homem-Terra". }\end{array}$ \\
\hline Objetivos & $\begin{array}{c}\text { Educação } \\
\text { ambiental, } \\
\text { internacional e } \\
\text { para o } \\
\text { desenvolvimento. }\end{array}$ & $\begin{array}{c}\text { Aprofundar a } \\
\text { compreensão } \\
\text { espacial das } \\
\text { múltiplas relações } \\
\text { entre homem e } \\
\text { natureza. }\end{array}$ & $\begin{array}{l}\text { Desenvolvimento } \\
\text { da autonomia } \\
\text { frente à } \\
\text { globalização. }\end{array}$ & $\begin{array}{c}\text { Desenvolvimento } \\
\text { de competências } \\
\text { geográficas e } \\
\text { interdisciplinares } \\
\text { para o } \\
\text { desenvolvimento } \\
\text { sustentável. }\end{array}$ \\
\hline
\end{tabular}




\begin{tabular}{|c|c|c|c|c|}
\hline $\begin{array}{l}\text { Papel da } \\
\text { Geografia }\end{array}$ & $\begin{array}{l}\text { Possibilitar olhar } \\
\text { globalizado em } \\
\text { uma ótica } \\
\text { corresponsável. }\end{array}$ & $\begin{array}{l}\text { Lançar bases para } \\
\text { se pensar o } \\
\text { desenvolvimento } \\
\text { sustentável. }\end{array}$ & $\begin{array}{c}\text { A geografia } \\
\text { voltada para a } \\
\text { formação de uma } \\
\text { identidade } \\
\text { intercultural. }\end{array}$ & $\begin{array}{c}\text { Contribuição da } \\
\text { Geografia voltada } \\
\text { ao } \\
\text { Desenvolvimento } \\
\text { sustentável. }\end{array}$ \\
\hline $\begin{array}{l}\text { Organização } \\
\text { Curricular }\end{array}$ & $\begin{array}{l}\text { Currículo voltado } \\
\text { para dados gerais } \\
\text { e enciclopédicos. }\end{array}$ & $\begin{array}{l}\text { Currículo voltado } \\
\text { para o meio } \\
\text { ambiente, } \\
\text { desvinculado às } \\
\text { questões políticas } \\
\text { e preocupado com } \\
\text { a sustentabilidade. }\end{array}$ & $\begin{array}{c}\text { Currículo voltado } \\
\text { para } \\
\text { aprendizagens } \\
\text { úteis à } \\
\text { comunidade, } \\
\text { promoção da } \\
\text { igualdade dos } \\
\text { gêneros e } \\
\text { identidade } \\
\text { cultural. }\end{array}$ & $\begin{array}{l}\text { Currículo } \\
\text { geográfico voltado } \\
\text { para educação e } \\
\text { desenvolvimento } \\
\text { sustentável. }\end{array}$ \\
\hline $\begin{array}{c}\text { Responsável } \\
\text { pelo } \\
\text { Ensino }\end{array}$ & $\begin{array}{l}\text { Centralidade nas } \\
\text { instituições, } \\
\text { escolares com } \\
\text { foco na figura do } \\
\text { professor (saber } \\
\text { generalista). }\end{array}$ & $\begin{array}{l}\text { Professores e } \\
\text { alunos são } \\
\text { corresponsáveis } \\
\text { pelo ensino de } \\
\text { Geografia, tendo } \\
\text { em vista a } \\
\text { preocupação com } \\
\text { o meio ambiente e } \\
\text { o } \\
\text { desenvolvimento } \\
\text { de práticas } \\
\text { sustentáveis. No } \\
\text { entanto o } \\
\text { professor possui } \\
\text { maior peso na } \\
\text { relação com o } \\
\text { conteúdo. }\end{array}$ & $\begin{array}{l}\text { Centralidade em } \\
\text { todos os atores e } \\
\text { parceiros da } \\
\text { escola - } \\
\text { professores e } \\
\text { formadores, } \\
\text { educandos, pais e } \\
\text { famílias, grupos de } \\
\text { filiação, } \\
\text { comunidade mais } \\
\text { próxima e } \\
\text { autoridades locais. } \\
\text { Sendo o professor } \\
\text { articulador de } \\
\text { todos os } \\
\text { envolvidos. }\end{array}$ & $\begin{array}{c}\text { Centralidade das } \\
\text { informações e } \\
\text { tecnologias da } \\
\text { comunicação (ITC) } \\
\text { para o } \\
\text { Desenvolvimento } \\
\text { Sustentável em } \\
\text { Geografia, sendo o } \\
\text { professor } \\
\text { mediador do } \\
\text { processo, } \\
\text { necessitando } \\
\text { dominar todas as } \\
\text { tecnologias, } \\
\text { competências e } \\
\text { habilidades para } \\
\text { ensinar o } \\
\text { conteúdo. }\end{array}$ \\
\hline
\end{tabular}

Fonte: Elaboração do autor FIGUREIREDO JUNIOR (2018), com base nas Carta Internacional pela educação Geográfica 1992; Nova Carta Internacional sobre Educação Geográfica (2000); 46ª Conferência Internacional da Unesco em Genebra (2001); e, Declaração de Lucerne (2007).

A exposição do Quadro 01, aponta as principais diferenças entre os documentos, dando possibilidade de compreensão das relações de influências dessas perspectivas nas orientações institucionais em uma relação direta entre local e global, no que tange o exercício hegemônico no lugar, conforme Santos (2017).

Pode-se compreender que o Neoliberalismo impôs uma visão unilateral e hegemônica em torno da educação nos países periféricos. Essa visão, exerceu 
fortes influências nas produções de orientações de Educação Geográfica para o ensino na Educação Básica. Observando esse contexto, é interessante pensar que:

Essa ação política pode, em muitos casos, ser orientada, apenas para um interesse particular e específico, frequentemente o da atividade hegemônica no lugar. Mas este é, apenas um primeiro momento. As atividades que, complementares ou não, têm uma lógica diversa da atividade dominante, provocam, a partir do seu conflito de preocupações, um debate acaba por interessar ao conjunto da sociedade local. E o resultado é a busca de uma sistema de reivindicações mais abrangentes, adaptados às contingências da existência comum, no espaço da horizontalidade (SANTOS, 2017, p. 288).

A ação hegemônica no lugar provoca contradições diretas nas práticas e concepções de Educação Geográfica na escola. Os(as) profissionais do ensino de Geografia, se inserem nesse contexto complexo de influências institucionais que, muitas vezes, representam o interesse Hegemônico no lugar, conforme apontado nas orientações internacionais para a Educação geográfica e seus possíveis desdobramentos nos países periféricos.

Enquanto alternativas de resistência, é interessante compreender o contexto de atuação objetiva de professores(as) de Geografia na Educação Básica, no Estado do Paraná. Desse modo, as Diretrizes Curriculares da Educação Básica para Geografia (DCE, 2008). A estrutura funcional de composição dos quadros efetivos e projetos de formação continuada podem orientar uma reflexão em torno das complexas relações que produzem concepções de Educação Geográfica, partindo dos sujeitos atuantes nos espaços escolares.

Na sequência, será realizado esforço de exposição e reflexão em torno das estruturas de carreira e aspectos materiais da atuação dos(as) professores(as) de Geografia, na Educação Básica do Paraná, atuantes no município de Francisco Beltrão. O recorte desses profissionais se deu por conta do tempo de pesquisa (dois anos a nível de Mestrado) e a viabilidade de contato direto com as pessoas envolvidas para realização de entrevistas e desenvolvimento de questionário.

A primeira vista, percebe-se maior número de mulheres atuantes enquanto professores de Geografia, portanto, no próximo tópico será utilizado o gênero 
feminino, quando for indicado trechos, citações ou inferências referente aos profissionais entrevistados(as).

\section{PROFESSORAS DE GEOGRAFIA DA EDUCAÇÃO BÁSICA DE FRANCISO BELTRÃO/PR}

A Constituição Federal de 1988, estabelece a Educação enquanto direito social, dever do Estado e da família, promovida e incentivada de modo colaborativo com a sociedade. Consoante a carta magna, a Lei n 9.394 de 1996, estabelece as Diretrizes e Bases da Educação Brasileira, regulamentando a prestação do serviço Educação à toda população brasileira.

O modelo de oferta educativa está pautado em um sistema de hierarquia e colaboração. O ministério da Educação e Cultura (MEC), Secretarias de Educação Estaduais e Municipais estão articuladas para o financiamento e viabilidade da oferta educacional no país (CAUS, 2015). Aqui cabe uma observação, do mesmo modo que a organização das orientações internacionais e locais se apresentam em redes de influência, a estrutura institucional educativa brasileira segue o mesmo padrão, formando tessituras com nós de centralização e fluxos de descentralização de poder (RAFFESTIN, 1993).

Na esfera de atuação do Paraná, essa estrutura organizativa se dá através dos órgãos regionais de educação, contemplando municípios específicos dentro de um campo de atuação:

A secretaria Estadual de Educação (SEED), do Paraná, é constituída por Núcleos Regionais de Educação (NRE), a fim de poderem melhor administrar o sistema educacional do Estado. No total existem 32 (trinta e dois) NREs: Área Metropolitana Norte; Área Metropolitana Sul; Apucarana; Assis Chateaubriand; Campo Mourão; Cascavel; Cianorte; Cornélio Procópio; Curitiba; Dois Vizinhos; Foz do Iguaçi; Francisco Beltrão; Goioerê; Guarapuava; Ibati; Ivaiporã; jacarézinho; Laranjeiras do Sul; Loanda; Londrina; Maringá; Paranavaí; Pato Brando; Pitanga; Ponta Grossa; Telêmaco Borba; Toledo; Umuarama; União da Vitória; Wenceslau Braz. (CAUS, 2015, p.33). 
Francisco Beltrão localiza-se na mesorregião Sudoeste do Paraná, abriga a sede do Núcleo Regional de Educação (NRE) da Secretaria de Estado de Educação e Desenvolvimento (SEED). Contempla Município de Ampére, Barracão, Bela Vista da Caroba, Bom Jesus do Sul, Capanema, Enéas Marques, Flor da Serra do Sul, Manfrinópolis, Marmeleiro, Pérola d'Oeste, Pinhal de São Bento, Planalto, Pranchita, Realiza, Renascença, Salgado Filho, Santa Izabel do Oeste e Santo Antônio do Sudoeste.

Respeitando perspectiva Federativa de organização Nacional, compreendendo a União enquanto junção dos estados federativos com autonomia e independência relativos, o Paraná se articula aos aspectos organizativos Nacionais (LENZA, 2011). A prestação de serviços de Educação Básica encontram eco ressonância na Constituição Federal de 1988, visto que a Constituição do Paraná de 1989, estabelece enquanto suas atribuições:

\footnotetext{
I - Ensino Fundamental, obrigatório e gratuito, inclusive para os que a ele não tenham tido acesso na idade própria; II - progressiva universalização do ensino médio gratuito; III - Ensino público noturno, fundamental e médio, adequado às necessidades do educando, assegurando o mesmo padrão de qualidade do ensino diurno; IV - atendimento educacional especializado gratuito aos portadores de deficiência, preferencialmente na rede regular de ensino; $\mathrm{V}$ Acesso aos níveis mais elevados do ensino, da pesquisa e da criação artística, segundo a capacidade de cada um; VI - organização do sistema estadual de ensino [...]. (PARANÁ, 1980, S/P).
}

A garantia de fornecimento de educação pública e gratuita no município de Francisco Beltrão para acesso a toda a população, é realizado por 17 (dezessete) instituições de ensino públicas estaduais, dentre elas, 01 (um) colégio agrícola; 02 (dois) colégios de educação básica para jovens e adultos e 14 (quatorze) colégios de Ensino Fundamental, Médio e profissionalizante. Atuando no ensino de Geografia, encontra-se um total de 35 (trinta e cinco) professoras do Quadro Próprio do Magistério (QPM). Essas informações podem ser encontradas no portal transparência do governo estadual. 
O ingresso no Quadro Próprio do Magistério (QPM), ocorre mediante concurso público por provas e títulos, há também, indicativo de valorização da careira docente na educação básica estabelecido em lei constitucional do Estado:

Art. 178. O ensino será ministrado com base nos seguintes princípios:

I - Igualdade de condição para acesso e permanência na escola, vedada qualquer forma de discriminação e segregação;

II - Gratuidade de ensino em estabelecimentos mantidos pelo Poder Público estadual, com isenção de taxas e contribuição de qualquer natureza;

III - Liberdade de aprender, ensinar, pesquisar e divulgar o pensamento a arte e o saber;

IV - Valorização dos profissionais do ensino, garantindo-se, na forma da lei, planos de carreira para todos os cargos do magistério público, piso salarial de acordo com o grau de formação profissional e ingresso, exclusivamente por concurso de provas e títulos, realizado periodicamente, sob regime jurídico adotado pelo Estado;

V - Garantia de padrão de qualidade em toda a rede e níveis a ser ficada em lei; VI - Pluralismo de ideias e de concepções pedagógicas e religiosas, e coexistência de instituições públicas e privadas de ensino;

VII - Asseguramento da pluralidade de oferta de ensino de língua estrangeira na rede pública estadual de educação. (PARANÁ, 1989, SP).

A aprovação das profissionais atuantes em Francisco Beltrão, ocorreu mediante concurso público de provas e títulos, visto que na legislação vigente, o ingresso em QPM inicia no Nível I, Classe I da Carreira em conformidade do dispositivo normativo Lei Complementar 103 de 15 de março de 2004, que estabelece:

Art. $4^{\circ}$ Para efeito desta Lei, entende-se por:

I - CARGO: centro unitário e indivisível de competência e atribuições, criado por lei, com denominação própria, em números certos e remuneração paga pelo Poder Público, provido e exercido por um titular hierarquicamente localizado na estrutura organizacional do serviço público;

II - CARREIRA: conjunto de Níveis e Classes que definem a evolução funcional e remuneratória do Professor, de acordo com a complexidade de atribuições e grau de responsabilidade;

III - NÍVEL: divisão da Carreira segundo o grau de escolaridade, titulação ou certificação no Programa de Desenvolvimento Educacional;

$\mathrm{VI}$ - DOCÊNCIA: atividade de ensino desenvolvida pelo Professor, direcionada para aprendizagem do aluno e consubstancialmente na regência de classe; VIII - HORA-ATIVIDADE: tempo reservado ao Professor em exercício de docência para estudos, avaliação e planejamento, realizado preferencialmente de forma coletiva (PARANÁ, 2004, S/P). 
Em âmbito legislativo e administrativo, os profissionais QPM gozam de estabilidade, expectativa salarial progressiva e hora-atividade remunerada. Sua carreira, se estrutura em 6 (seis) níveis, cada um composto por 11 (onze) classes. No tocando ao município de Francisco Beltrão, em 2018 encontrava-se 35 (trinta e cinco) profissionais QPM, atuando na rede pública estadual. Consoante ao objeto do estudo de caso desenvolvido, foi possível entrevistar 29 (vinte e nove) dessas profissionais, visto que 6 (seis), estavam usufruindo de licenças específicas portanto, afastadas de suas funções.

O encontro com as profissionais elencadas ocorreu de modo individual, no período de março e abril de 2018. Os diálogos ocorreram, majoritariamente, no momento de hora-atividade, em algumas ocasiões, foi realizado em intervalos ou após a aula. Nessas oportunidade, era explicado os objetivos da pesquisa e orientado assinatura do Termo de Consentimento Livre e Esclarecido (TCLE). Esse procedimento, garantia direito ao anonimato e escolha de participar ou não do estudo.

Em termos quantitativos, a primeira informação identificada foi o número de 22 (vinte e duas) mulheres e 7 (sete) homens, demonstrando assim maioria feminina na oferta do ensino de Geografia nas escolas estaduais do município. Continuando nessa sistemática, a Tabela 01 apresenta total de profissionais efetivos (entrevistadas) e as instituições de suas formações.

Tabela 1 - Total de professoras(es) efetivas(os) de Geografia formados e suas respectivas instituições de formação.

\begin{tabular}{lc}
\hline Universidade & Quantidade \\
\hline FACIBEL & 14 \\
UNIOESTE & 13 \\
UFGD & 01 \\
UNESP & 01 \\
TOTAL & 29 \\
\hline
\end{tabular}

Fonte: Elaboração do autor FIGUREIREDO JUNIOR (2018). 
Em sua maioria, as entrevistadas se formaram na Faculdade de Ciências Humanas de Francisco Beltrão (FACIBEL), instituição que se transforma na Universidade Estadual do Oeste do Paraná (UNIOESTE) Campus de Francisco Beltrão, mediante Lei Estadual n 12.235/1998 e Decreto Estadual 995/1999. Enquanto Facibel, 93\% das entrevistadas realizaram graduação nessa unidade, e apenas $4 \%$ em instituições diversas fora do município, sendo elas a Universidade Federal da Grande Dourados (UFGD) em Mato Grosso do Sul e a Universidade Estadual Paulista (UNESP) em São Paulo.

Tratando-se de formação, 03 (três) concluíram a graduação no fim da década de 1980 (especificamente 1987 e 1989), 12 (doze no decorrer da década de 1990 (três em 1990 e 1994, dois em 1998 e um em 1999), a partir dos anos 2000 foram 08 (oito) (uma nos anos 2000, 2002, 2010, 2011 e 2012, duas em 2007). Apenas 23 (vinte e três) entrevistadas responderam essa questão - algumas não se lembravam, outras optaram por não responder, salientando motivos particulares.

Referente à pós-graduação, apenas uma das professoras não possuía. AS profissionais que declararam pós-graduação, observou-se 53 (cinquenta e três) especializações, 10 (dez) mestrados e 01 (uma) cursando doutorado e 05 (cinco) possuía título do Programa de Desenvolvimento Educacional (PDE)

Importante destacar que o PDE foi uma política de governo criada para incentivar a qualificação e formação continuada, para profissionais da educação no Estado do Paraná. Enquanto política de governo, foi estabelecida em 2004 e muito contribuiu para a qualificação dos profissionais atuantes nas escolas da rede básica de educação pública (MARTINS, 2013).

Totalizaram 69 (sessenta e nove) cursos em nível de pós-graduação, conforme: 
Tabela 2 - Quantidade total de Pós-Graduação divididas pelo tipo.

\begin{tabular}{ccccccc}
\hline $\begin{array}{c}\text { Tipo de Pós- } \\
\text { Graduação }\end{array}$ & Especialização & Mestrado & Doutorado & PDE & Total \\
\hline Quantidade & 53 & 10 & 1 & 5 & 69 \\
\hline
\end{tabular}

Fonte: Elaboração do autor FIGUREIREDO JUNIOR (2018).

Cada uma das profissionais apresentou pelo menos duas especializações cada. Alguns casos, foi possível identificar três ou mais especializações por parte de cada entrevistada. Em se tratando do mestrado, não ocorreu tal fenômeno, em regra era apenas um, para cada profissional que declarou ter esse nível de qualificação. Já no caso do Doutorado, a previsão de término era para 2020, e apenas um declarou estar cursando. Das professoras mestras, três delas também contavam com o PDE e mais especializações, as outras duas, era apenas especialização e PDE.

A quantificação das pós-graduandas trabalhando com o ensino de Geografia, indica que houve trânsito acadêmico em torno de processos de pesquisa e produção do conhecimento. Essa inserção e qualificação, reflete diretamente nas práticas escolares e na carreira dessas profissionais. Além dos benefícios salariais, essa inserção fomenta trocas de experiência entre Educação Básica e Superior, fundamental para qualificar a educação brasileira. 
Tabela 3 - Ano de conclusão e quantidade conclusão de pós-graduações, das (os) professoras (es) de Geografia efetivas (os) lotadas (os) em Francisco Beltrão/PR.

\begin{tabular}{cc}
\hline ANO & $\begin{array}{c}\text { QUANTIDADE DE PÓS- } \\
\text { GRADUAÇÃO FINALIZADA }\end{array}$ \\
\hline 1997 & 01 \\
2000 & 02 \\
2001 & 01 \\
2003 & 01 \\
2009 & 01 \\
2010 & 02 \\
2011 & 02 \\
2012 & 03 \\
2015 & 03 \\
2016 & 01 \\
2017 & 05 \\
2018 & 02 \\
TOTAL & 24 \\
\hline
\end{tabular}

Fonte: Elaboração do autor FIGUREIREDO JUNIOR (2018).

A Tabela 03, apontou os anos de conclusão e a quantidade de pósgraduações realizados no período. Foram mencionadas 16 (dezesseis) instituições, públicas e privadas, de curso das pós-graduações, foram Universidade Estadual do oeste do Paraná (UNIOESTE), Universidade do Centro Oeste (UNICENTRO), Centro Universitário Internacional (UNINTER), Faculdade de Ampére/PR (FAMPER), Universidade do Vale do Itajaí (UNIVALI), Faculdade Internacional de Curitiba (FACINTER), Faculdade São Braz, Universidade Estadual Paulista (UNESP), Faculdade São Luíz, Universidade Tecnológica Federal do Paraná (UTFPR), DP Consultoria, Universidade Federal Fronteira Sul (UFFS), Centro Universitário Campos de Andrade (UNIANDRADE), UNOPAR, Faculdade Camões e a Universidade Estadual do Mato Grosso do Sul (UEMS). 
Pondo os anos de realização das pós-graduações em evidência, nota-se que majoritariamente ocorreram pós 2010. Esse dado, indica que essas profissionais formadas principalmente na década de 1990 - ingressaram na pós-graduação no decorrer de seus exercícios profissionais. Isso evidencia a importância de condições materiais e políticas públicas voltadas para qualificação profissional.

Tabela 4 - Quantidade total de Pós-Graduação das(os) professoras(es) efetivas(os) de Geografia que trabalham em Francisco Beltrão/PR e as Instituições onde foram realizadas.

\begin{tabular}{cc}
\hline UNIVERSIDADE & $\begin{array}{c}\text { QUANTIDADE DE PROFESSORES QUE } \\
\text { REALIZARAM A PÓS-GRADUAÇÃO }\end{array}$ \\
\hline UNIOESTE & 14 \\
UNICENTRO & 07 \\
UNINTER & 03 \\
FAMPER & 03 \\
UNIVALE & 02 \\
FACINTER & 02 \\
SÃO BRAZ & 02 \\
UNESP & 02 \\
SÃO LUIS & 01 \\
UTFPR & 01 \\
DP CONSULTORIA & 01 \\
UFFS & 01 \\
UNIANDRADE & 01 \\
UNOPAR & 01 \\
FACULDADE CAMÕES & 01 \\
UEMS & 01 \\
\hline
\end{tabular}

Fonte: Elaboração do autor FIGUREIREDO JUNIOR (2018).

Incentivos políticos para formação continuada, planos de cargos e carreiras estruturados, valorização salarial e perspectivas de ampliar conhecimento, são fatores importantes que promovem a qualificação de todos(as) profissionais da educação brasileira. Desse modo, se tornou mais atrativo o ingresso nesses campos profissionais. 
Maior parte dos cursos de pós-graduação foram realizados na Unioeste. Cabe aqui salientar impacto positivo dessa instituição para a educação local, demonstra que o serviço prestado pelos profissionais da Universidade reflete diretamente na melhora qualitativa da educação básica de Francisco Beltrão.

Outro ponto que se destacou no estudo de caso, foi referente ao tempo de trabalho na rede pública de ensino, apresentada na Tabela 05. A exposição se organizou por períodos, primeiro menos de um ano, depois entre uma quatro anos, cinco a nove anos, dez a quinze anos, assim por diante, segue:

Tabela 5 - Tempo de trabalho na rede pública das(os) professoras(es) efetivas(os) de Geografia, lotadas(os) no Município de Francisco Beltrão/PR.

\begin{tabular}{cc}
\hline ESTIMATIVA DE TEMPO & QUANTIDADE DE PROFESSORES \\
\hline MAIS DE 30 ANOS & 04 \\
DE 20 A 29 ANOS & 12 \\
DE 16 A 19 ANOS & 00 \\
DE 10 A 15 ANOS & 05 \\
DE 05 A 09 ANOS & 02 \\
DE 01 A 04 ANOS & 06 \\
MENOS DE 01 ANO & 00 \\
\hline
\end{tabular}

Fonte: Elaboração do autor FIGUREIREDO JUNIOR (2018), com base nas respostas do questionário desenvolvido junto às entrevistadas em abril de 2018.

Em sua maioria, as profissionais atuavam na rede há mais de vinte anos, demonstrando a importância dessa atuação em âmbito local. Representam grande influência na formação geográfica básica dos(as) moradores(as) do município. Articulado a perspectiva de tempo de serviço, coletou-se informação referente a quantidade de escolas da rede pública, que atuavam. A quantidade máxima de unidades escolares foi 05 (cinco) e mínimo 01 (um): 
Tabela 6 - Quantidade de escolas que atuam as (os) professoras (es) de Geografia efetivas (os) lotadas (os) no Município de Francisco Beltrão/PR.

\begin{tabular}{cc}
\hline NÚMERO DE ESCOLAS & $\begin{array}{c}\text { QUANTIDADE DE PROFESSORES QUE } \\
\text { TRABALHAM }\end{array}$ \\
\hline UMA & 06 \\
DUAS & 12 \\
TRÊS & 06 \\
QUATRO & 03 \\
CINCO & 02 \\
TOTAL & 29 \\
\hline
\end{tabular}

Fonte: Elaboração do autor FIGUREIREDO JUNIOR (2018), com base nas respostas do questionário desenvolvido junto às entrevistadas em abril de 2018.

A exposição desses dados provoca reflexão em trono das condições objetivas para realização de uma Educação Geográfica de qualidade. A demanda de serviços exigidos por trabalhar em mais de uma escola, provoca dificuldades para o planejamento coletivo e ações docentes dessas profissionais. Essas condições adversas, interferem diretamente nas concepções de Educação Geográfica apresentado por elas.

\section{QUE É EDUCAÇÃO GEOGRÁFICA PARA VOCÊ, PROFESSORA?}

A segunda parte do estudo de caso realizado se voltou para identificar concepções de Educação Geográfica, partindo da fala das profissionais atuantes na Educação Básica, no município de Francisco Beltrão. Os instrumentos de pesquisa utilizados possibilitaram evidenciar e categorizar três eixos principais de concepções.

Em sua maioria, as professoras apresentavam uma visão de Educação Geográfica em perspectiva de transformações sociais e formação do pensamento crítico. Essa leitura, se articulava a um pressuposto de formação humana de caráter político voltada para a emancipação social. Com efeito, a compreensão do espaço se fundamenta um esforço de enfrentamento e resistência das desigualdades em todos os seus aspectos (DCE, 2008). 
A centralidade dessa leitura se aproxima do Materialismo Histórico e Dialético, principalmente no que trata “Em verdade, não é a nossa visão do mundo que mudou, o que mudou foi o próprio mundo" (SANTOS, 2017, p. 198). Essa mutabilidade se associa aos movimentos contraditórios presentes desde a origem da civilização "No próprio momento em que a civilização começa, começa a produção a basear-se no antagonismo das ordens, dos estados, das classes, enfim no antagonismo do trabalho acumulado e do trabalho imediato" (MARX, 2018, p. 58).

A Educação Geográfica nesse contexto se apresenta, para a Professora I “[...] fundamental, para entender as relações sociais atuais para modifica-la de maneira consciente" (Professora I). Dialogando com essa exposição Professora N argumentou: "[...] nas escolas, a geografia ajuda o aluno a pensar nas questões políticas e econômicas e inclusive a saber votar" (Professora N).

Ambas as professoras apontaram uma Educação geográfica marcada pelo vínculo entre o conhecimento geográfico e a realidade social dos estudantes. Essa linha de pensamento apareceu em várias entrevistas, desse modo dava-se importância para formação de sujeitos críticos e transformadores do espaço com consciência de suas ações:

O aluno precisa saber o que fazer com as informações e isso pode ser o ponto central da educação geográfica: ensinar para a vida, para saber e entender que o que acontece nos lugares em que ele vive é parte de um mundo globalizado, da mesma forma que as guerras, as lutas, os embates que acontecem mundo afora, mesmo que sejam distantes “CALLAI, 2012, p. 74).

Essa síntese ajuda elucidar o eixo Materialista Histórico e Dialético, visto a aproximação das ideias das profissionais entrevistadas nessa categoria. Destacase também que "Proporcionar ao aluno condições para analisarem criticamente o espaço em que vivem e atribuindo a responsabilidade enquanto agentes de transformação" (Professora U), também acaba se inserindo nessa categoria, junto a Professora C ao apontar que "No cotidiano, ela tem papel de melhoria constante 
nos espaços onde o aluno se encontra (se percebe como sujeito responsável pelo espaço onde vive)".

Outro aspecto evidenciado em torno da Educação Geográfica, se dá a partir da compreensão das contradições inerentes ao modo de produção capitalista, pois "As relações sociais são camufladas, nesse aspecto os alunos precisam visualizar as intenções veladas no bojo social" (Professora E). Esse posicionamento, em torno dos antagonismos de classe, apresenta diálogo direto com a perspectiva de relações sociais de produção em contraposição ao avanço da força produtiva (MARX, 2017).

As profissionais próximas ao eixo Materialista Histórico e Dialético, compreendiam a realidade partindo de suas complexidades e uma Educação geográfica propositiva. Ao mesmo tempo que ela colabora em desvelar as nuances das relações sociais, possibilita a elaborar estratégias de ação para a transformação espacial.

Em razão dessa complexidade que é crescente, o cidadão não consegue sozinho e espontaneamente compreender seu espaço de modo mais articulado e mais crítico (...). O conhecimento mais integrado da espacialidade requer uma instrumentalização conceitual que torne possível aos alunos apreensão articulada desse espaço (CAVALCANTI, 1998, p. 11-12).

As professoras que se aproximaram do eixo Materialista Histórico e Dialético somaram um total de 22 (vinte e duas) profissionais inquiridas, representando $75,85 \%$ do total de participantes do estudo de caso. Já o outro eixo, também considerava uma dimensão de transformação social, mas a centralidade da Educação Geográfica se pautava em aspectos ambientais e de preservação da natureza.

Para elas, Educação Geográfica possuía “Função em fazer o cidadão compreender o mundo em que vivemos nos aspectos naturais e sociais (as dificuldades da humanidade)" (professora C3). Dialogando com tal perspectiva, percebe-se "Fundamental na orientação da sociedade na busca de melhoria de vida, 
saúde, equilíbrio ambiental e social para compreender o país em que vivemos" (Professora B2).

Essa concepção de Educação Geográfica, se aproxima no que trata “Entender a relação homem/natureza pressupõe compreender complexas interconexões, onde se interpenetram estruturas sociais, políticas, econômicas e ideológicas" (WALDMAN, 2002, p.18). Nota-se, aqui, articulação com as orientações da Declaração de Lucerne (2007), na perspectiva de "Terra-Humano", Casa comum" e “Família global” (HAUBRICH; REINFORIEDE; SHLEICHER, 2007).

Com efeito, "se o aluno tem uma compreensão do que os seres humanos já fizeram ele (aluno) poderá fazer de modo diferente (para melhor: saber se localizar para agir, escala) (Professora F). Aqui se destaca outra característica dessa categoria, a noção de passado - a história dos antepassados para pensar no presente e projetar o futuro.

Essas inferências possibilitam aproximar essas professoras em uma categoria Histórico e Ambiental. Não obstante, a Educação Geográfica se torna "educação sobre as relações entre sociedade e natureza" (Professora A1). Essa parcela de entrevistadas representaram $10,34 \%$ das profissionais, um total de 03 (três) professoras.

O terceiro eixo de aproximação de concepções se destacou dos dois anteriores. Nesse, a centralidade se dava na ideia de percepção do estudante. Uma educação geográfica que busque "Começar a desenvolver percepção que ele tem identidade, para com seu espaço de sua vivência. Se perceber parte dos processos que produzem o espaço Geográfico" (professora H).

Aqui pode-se salientar aspectos da subjetividade, centralizava a valorização dos saberes e práticas das experiências de vida de cada estudante, portanto a Educação Geográfica se tornava "Um complemento, articulado com os saberes das vivências dos alunos" (Professora P). Ora, a importância são "Os temas a serem abordados - percepções, atitudes e valores - preparam-nos, primeiramente a compreender nós mesmos" (TUAN, 1980, p.01). 
Essa perspectiva subjetiva pode ser identificada também na $46^{\text {a }}$ Conferência Internacional da Unesco em Genebra (2001) - promover uma formação de identidade intercultural, enquanto responsabilidade do ensino da Geografia (conforme já exposto no Quadro 01). Nesse eixo de concepções, a Educação Geográfica se faz mediante o elo afetivo entre lugar e pessoa, valoriza cada indivíduo em sua complexidade, observa-se a leitura espacial, partindo das questões sociais postas a toda a humanidade.

A presença de uma Topofilia, entendida como "[...] o elo afetivo entre a pessoa e o lugar ou ambiente físico. Difuso como conceito, vívi do e concreto como experiência pessoal [...]" (TUAN, 1980, p.5). Essa categoria, Subjetivo Fenomenológico, representaram 13,79\% da parcela total, das professoras entrevistadas. Em resumo, assim se organizaram as categorias elencadas:

1) Eixo Materialista Histórico e Dialético, profissionais que demonstraram centralidade na preocupação do domínio dos conhecimentos geográficos, para ler e produzir espaço de modo crítico. A ação dos estudantes é ponto de partida e objetivo final da Educação Geográfica. Todos(as) envolvidos no processo de ensino e aprendizagem possuem potência crítica, consciente e transformadora da realidade.

2) Eixo Histórico Ambiental, professoras que se preocupavam com o domínio dos conhecimentos geográficos em uma compreensão histórica da relação entre seres humanos e natureza. Cabe a Educação Geográfica o olhar crítico, questionar e provocar maneiras diferenciadas de ser e estar no mundo, sobretudo em vista dos impactos ambientais gerados pelas ações antrópicas. A sustentabilidade se torna o caminho possível para a formação desse sujeito para o mundo.

3) Eixo Subjetivo/fenomenológico, as docentes que apregoavam domínio do conhecimento geográfico para valorização das experiências pessoais das vivências dos estudantes de modo individual. Sua identidade em perspectiva do pertencimento ao lugar onde vive, suas origens e relações afetivas a partir das 
contradições existentes. Formar pessoas para estar e viver o mundo de múltiplas maneiras.

Tabela 7 - Eixos de compreensão sobre educação geográfica por parte das (os) professoras (es) de Geografia que trabalham nos colégios estaduais de Francisco Beltrão/PR.

\begin{tabular}{ccc} 
CATEGORIA & QUANT. & $\%$ \\
\hline Materialismo Histórico e Dialético & 22 & $75,85 \%$ \\
Subjetiva/Fenomenológica & 4 & $13,79 \%$ \\
Histórica ambiental & 3 & $10,34 \%$ \\
TOTAL & 29 & $99,98 \%$
\end{tabular}

Fonte: Elaboração do autor FIGUREIREDO JUNIOR (2018), com base nas respostas do questionário desenvolvido junto às entrevistadas em abril de 2018.

A Tabela 07, apresenta a organização das categorias encontradas. O ponto de convergência se deu na preocupação transformadora. Todas as entrevistadas não se apresentaram conformadas com o status quo, cada uma - ao seu modo apresentou compromisso com uma Educação Geográfica com viés emancipatório.

A escolha dos eixos e sua sistematização, foi ponto central do estudo de caso desenvolvido. Foram muitas as dificuldades, mas os dados coletados junto aos estudos teóricos e orientações feitas foram fundamentais para chegar na exposição feita nesse texto. Cabe aqui o apreço e agradecimento à todas(os) envolvidas(os) nessa pesquisa. Há clareza de que o caminho está longe do término, agora o esforço se dará em aprofundar ainda mais nas análises desses eixos buscando entende-los em uma perspectiva de práxis. Esse é o ponto de partida para outras pesquisas.

\section{CONSIDERAÇÕES FINAIS}

Experiência trocadas com várias(os) profissionais professoras(es), pesquisadoras(es), amigas(as) e familiares possibilitaram um canal fértil de 
comunicação, fundamental para a produção da pesquisa em tela. Os resultados aqui apresentados são frutos de esforço coletivo, dentro de um contexto árido de valorização da produção do conhecimento no Brasil. Poucos investimentos e sistemáticos cortes de verbas encampados por gestores governamentais mal intencionados.

A elaboração das categorias e as análises realizadas, sejam pelas leituras flutuantes ou através das categorizações (BARDIN, 2011), permitiram vislumbrar as concepções das profissionais atuantes no Ensino de Geografia na Educação Básico de Francisco Beltrão. Preocupação social, compromisso com o ensino de qualidade e resistência na defesa pela educação pública e gratuita estão presentes na atuação dessas professoras.

As contradições são visíveis, a Educação do país possui marcas fortes de avanços e retrocessos coexistindo, desencadeando produções espaciais diferenciadas a todo o momento. É nessa rede de influências, exercícios hegemônicos e resistências que se origina a Educação Geográfica, em suas muitas facetas. Não cabe aqui, apontar qual delas é a melhor ou aquela que deve ser instigada, no entanto sabe-se que é a classe trabalhadora (que vivencia diariamente as misérias do capitalismo) que de fato necessitam dela.

Educação Geográfica não se afastará do compromisso de garantir acesso universal aos conhecimentos geográficos produzidos historicamente. Isso, pressupõe compreender o papel de professores da Educação Pública no Brasil, onde muitas pessoas acabam não possuindo a qualidade de vida necessária para viver e ser mais.

\section{REFERÊNCIAS}

BARDIN, L. Análise de conteúdo. Tradução de Luiz Antero Neto, Augusto Pinheiro. Edições 70: São Paulo, 2011. 
BATISTA, P. N. O consenso de Washington: a visão neoliberal dos problemas latinoamericanos. In BATISTA, P.N. et al. Em defesa do interesse Nacional: desinformação e alienação do patrimônio público. São Paulo: Paz e Terra, 1995.

BRASIL. Constituição (1988). Constituição da República Federativa do Brasil. Brasília: Presidência da República Casa Civil Subchefia para assuntos Jurídicos. 1988. Disponível em: http://www.planalto.gov.br/ccivil_03/constituicao/constituicaocompilado.htm. Acesso em: 23 mai. 2018.

CALLAI, H. C. Educação geográfica: ensinar e aprender geografia. In Conhecimentos escolares e caminhos metodológicos, Org. CASTELLAR, Sonia Maria Vanzella; MUNHOZ, Gislaine Batista; ARROIO, Agnaldo. [S.I: s.n.], 2012, p.73-87.

CAUS, F. R. O emprego do trabalho de campo no ensino de geografia das escolas do Núcleo Regional de Educação de Francisco Beltrão - PR. Dissertação apresentada no Programa de Pós-Graduação (Mestrado e Doutorado em Geografia) Universidade Estadual do Oeste do Paraná - Campus de Francisco Beltrão/PR, 2015. Disponível em: http://tede.unioeste.br/bitstream/tede/1138/1/Francieli_Caus.pdf. Acesso em: 23 mai. 2018.

CAVALCANTI, L. de S. Geografia, escola e construção de conhecimento. Campinas. Papirus: São Paulo, Campinas, 1998.

DELORS, J.; et al. Educação um Tesouro a Descobrir: Relatório para a UNESCO da Comissão Internacional sobre Educação para o século XXI. Título original: "Learnig: the treasure within" UNESCO; MEC (Ministério da Educação e do Desporto): Cortez, impresso no Brasil em 1998.

DEMO, P. Metodologia científica em ciência sociais. - 3. ed. ver. e ampl. - 15. Reimpr. - Atlas: São Paulo, 2012.

FIGUEIREDO JUNIOR, J. S. de. Educação Geográfica: Concepções de professoras(es) de geografia da rede estadual de educação em Francisco Beltrão. Orientadores Rosana Cristina Biral Leme e Najla Mehanna Mormul, 2019. Disponível em: http://tede.unioeste.br/bitstream/tede/4677/5/Jalme\%20Santana\%20de\%20Figueiredo\%20Jr\%202019.pdf. Acesso em: 26 mar. 2021.

GODOY, A. S. Pesquisa qualitativa tipos fundamentais. In Revista de Administração de Empresas, São Paulo, v. 35, n.3, p. 20-29, Mai/Jun. 1995.

GONZÁLES, X. M. S; CLAUDINO, S. Educação geográfica no século XXI. Centro de Estudos Geográficos, Universidade de Lisboa, 2002.

HAUBRICH, H.; REINFRIED, S.; SCHLEICHER, Y. Declaração de Lucerne sobre a Educação Geográfica para o Desenvolvimento Sustentável. Visões Geográficas em Educação para o Desenvolvimento Sustentável. Procedimentos para o Simpósio Lucerne, Suíça. Geographiedidaktische Forschungen, vol. 42, Lucerne, 2007, p. 243-250. Disponível em: http://www.igu-cge.org/Charters-pdf/portuguese.pdf. Acesso em: 26 mar. 2021. 
JESUS, L.G. de. Os primeiros passos na geografia: a Pedagogia de Projetos em Prática no ensino Fundamental I. Dissertação (Mestrado em Geografia). Universidade Estadual de Londrina, Centro de Ciências Exatas, Programa de Pós-Graduação em Geografia, 2014. Disponível em: http://www.bibliotecadigital.uel.br/document/?view=vtls000194406. Acesso em: 26 mar. 2021.

LENZA, P. Direito Constitucional Esquematizado. São Paulo: Saraiva, 2011.

MARTINS, J. C. de S. A precarização do trabalho docente nas escolas estaduais de Marechal Cândido Rondon/PR: um estudo sobre os professores PSS. Dissertação (Mestrado em Geografia) - Universidade Estadual do Oeste do Paraná (Unioeste) Campus de Francisco Beltrão/PR, 2013.2 Disponível em: http://tede.unioeste.br/bitstream/tede/1102/1/Jessica_Carolina.pdf. Acesso em: 26 mar. 2021.

MARX, K. O Capital: Crítica da economia política: livro I. Tradução de Reginaldo Sant'Anna. - 35a ed. - Civilização Brasileira: Rio de Janeiro, 2017.

MARX, K. A miséria da filosofia: resposta à filosofia da miséria de Proudhon. Tradução Paulo Roberto Banhara. - São Paulo: Lafonte, 2018.

MINAYO, M. C. de S. Trabalho de campo: contexto de observação, interação e descoberta. In Pesquisa social: teoria, método e criatividade, Org.: MINAYO, M.C.S; DESLANDES, S.F; GOMES, R. (Série Manuais Acadêmicos). Vozes: Rio de Janeiro, Petrópolis, 2016, p. 56-71.

MORIN, E. Os sete saberes necessários à educação do futuro. Tradução de Cataria Eleonora F. da Silva e Jeanne Sawaya; revisão técnica de Edgard de Assis Carvalho. - 2. ed. rev. - São Paulo: Cortez; Brasília, DF: UNESCO, 2011.

NETO, M. F. de S. As atuais políticas educacionais no Brasil e os seus impactos no currículo básico de Geografia. Revista da Casa da Geografia de Sobral, Sobral, v. 4/5, p. 9-15, 2003.

PARANÁ, Constituição do Estado. Constituição do Estado do Paraná. Publicado no Diário Oficial $n^{\circ} 3116$ de 05 de Outubro de 1989. Disponível em: https://www.legislacao.pr.gov.br/legislacao/listarAtosAno.do?action=iniciarProcesso\&tipoAto= 10\&orgaoUnidade=1100\&retiraLista=true\&site=1. Acesso em: 26 mar. 2021.

PARANÁ. Lei complementar n 103, de 15 de março de 2004. Institui e dispõe sobre o Plano de Carreira do Professor da Rede Estadual de Educação Básica do Paraná e adota outras providências. Disponível em:

http://www.legislacao.pr.gov.br/legislacao/pesquisarAto.do?action=exibir\&codAto=7470\&indic e=1\&totalRegistros=1. Acesso em 25 mar. 2021.

PARANÁ. Lei complementar $n^{\circ}$ 130, de 20 de julho de 2010, Regulamenta o Programa de Desenvolvimento Educacional - PDE. Disponível em: http://www.educacao.pr.gov.br/arquivos/File/editais/leicomplementar1302010.pdf. Acesso em: 26 mar. 2021. 
RAFFESTIN, C. Por uma Geografia do Poder. Título original: Pour une géographie du pouvoir. Tradução: Maria Cecília França. Ática: São Paulo, 1993.

SANTOS, M. A natureza do Espaço: técnica e tempo, razão e emoção. $4^{a}$ ed. $5^{a}$ reimp. Universidade de São Paulo: São Paulo, 2017.

TUAN, Y. Topofilia: Um estudo da Percepção, Atitudes e Valores do Meio Ambiente. Tradução: DIFEL, São Paulo: Difusão Editorial S.A, 1980

UNESCO (United Nations Education, Scientific and Cultural Organization). Aprender a viver juntos: nós falhamos?. Síntese das reflexões e das contribuições extraídas da $46^{a}$ Conferência Internacional da Educação da UNESCO em Genebra - Suíça, ocorrida nos dias 5-8 de Setembro de 2001. Título original: Apprendre à vivre ensemble: avons-nous échoué? IBE, UNESCO: Brasília, 2003.

UNIÃO GEOGRÁFICA INTERNACIONAL (UGI)/Comissão da Educação Geográfica. Carta Internacional da Educação Geográfica. Tradução de Manuela Malheiro Dias Ferreira. Lisboa: Associação de Professores de Geografia, 1992. In: Fundamentos teóricos e práticos do Ensino de Geografia. Paulo César Medeiros. 2ª ed. Curitiba: IESDE Brasil S.A, 2010.

UNICEF (Fundo das Nações Unidas para a Infância). Plano de ação para satisfazer as necessidades básicas de aprendizagem. Aprovada pela Conferência Mundial sobre Educação para todos Jomtien, Tailândia - 5 a 9 de março de 1990. Disponível em: https://www.unicef.org/brazil/pt/resources_10230.htm. Acesso em: 26 mar. 2021.

WALDMAN, M. Ecologia e lutas sociais no Brasil. (Caminhos da Geografia) 6 ed. Contexto: São Paulo, 2002.

WCEFA (World Conference on Education for All/Conferência Mundial de Educação para Todos). Declaração mundial sobre educação para todos e plano de ação para satisfazer as necessidades básicas de aprendizagem. Jomtien Tailândia, 1990. Disponível em: https://www.unicef.org/brazil/declaracao-mundial-sobre-educacao-para-todos-conferenciade-jomtien-1990. Acesso em: 26 mar. 2021.

YIN, R. K. Estudo de caso: Planejamento e métodos. Tradução de Daniel Grassi. 2 $2^{\mathrm{a}}$ ed. Bookman: Porto Alegre, 2001.

\section{1 - Jaime Santana de Figueiredo Junior:}

Professor Efetivo na Secretaria Estadual de Educação de Mato Grosso, lotado na Escola Estadual Professor Fernando Leite de Campos https://orcid.org/0000-0003-0811-6617•jalmefigueiredo18@hotmail.com Contribuição: Pesquisa, escrita e revisão 


\section{2 - Nejla Mehanna Mormul:}

Professora na Universidade Estadual do Oeste do Paraná (UNIOESTE), curso de Geografia Licenciatura

https://orcid.org/0000-0002-7403-8197•najlamehanna@gmail.com

Contribuição: Escrita, revisão e orientação

\section{3 - Rosana Cristina Biral Leme:}

Professora na Universidade Estadual do Oeste do Paraná (UNIOESTE), curso de Geografia Licenciatura

https://orcid.org/0000-0001-9806-8772•rosanabiral@hotmail.com

Contribuição: Escrita, revisão e orientação

\section{Como citar este artigo}

JUNIOR, J. S. de F.; NEJLA, M. M.; LEME, R. C. B. Educação Geográfica: Concepções de professores de Geografia na Rede Estadual em Francisco Beltrão-PR. Geografia Ensino \& Pesquisa, Santa Maria, v.25, e40, p. 1-31, 2021. DOI 10.5902/2236499465088. Disponível em: https://doi.org/10.5902/2236499465088. Acesso em: dia mês abreviado. ano. 